\title{
Uma Experiência Psicanalítica na Clínica Escola
}

\section{A Psychoanalytical Experience in Clinical School}

\author{
Artur Julio de Albuquerque Juniorl, João Luiz Leitão Paravidini2, \\ Caio César Souza Camargo Prochno3
}

\begin{abstract}
Resumo
Este trabalho foi desenvolvido a partir de uma experiência psicanalítica na clínica escola de um curso de Psicologia. O caso construído retrata uma mãe que se encontra aliciada pelo gozo na relação com seu filho primogênito. A dimensão do olhar é destacada como uma via privilegiada, em que estar "só focada" no filho remete a estar "sufocada" na angustia desse enlace. O tratamento se direcionou para fazer operar a incidência da falta, pela qual a paciente pôde deixar de ser todamãe para vir a ser não-toda mulher. No fim, destaca-se ainda, o que uma análise porta de mais radical incompreensão.
\end{abstract}

Palavras-chave: Psicanálise. Caso clínico. Feminilidade.

\section{Abstract}

This work was developed from a psychoanalytical experience in the clinical school of a course of Psychology. The case building portrayed a mother who was wooed by the jouissance felt in her relationship with her eldest son. This glance was highlighted as a prime route, in which being "exclusively focused" on her son referred to being "suffocated" in the anguish of this connection. The treatment focused on the feeling of absence so that the patient could let go of the all-mother role to finally become a not-every woman. At the end, we highlighted the most radical misunderstandings of this analysis.

Keywords: Psychoanalysis. Clinical case. Femininity.

\footnotetext{
${ }^{1}$ Universidade Federal de Uberlândia, Uberlândia, Brasil. E-mail: artur26junior@gmail.com

${ }^{2}$ Universidade Federal de Uberlândia, Uberlândia, Brasil. E-mail: jlparavidini@gmail.com

${ }^{3}$ Universidade Federal de Uberlândia, Uberlândia, Brasil. E-mail: c.prochno@uol.com.br
} 


\section{Introdução}

Este relato se desdobra a partir de uma experiência psicanalítica na clínica escola de um curso de Psicologia em uma faculdade privada de Minas Gerais. A clínica escola dessa instituição oferece serviços gratuitos de psicoterapia individual à comunidade local, cumprindo um importante papel social e contribuindo para a formação dos graduandos do curso de Psicologia.

A atuação clínica nessa instituição tem duração de dois semestres e é constituída por duas atividades, os atendimentos na clínica escola e as supervisões com profissionais que oferecem esteio para a atividade. As supervisões, obrigatórias para a prática, aconteciam em grupo, com frequência semanal e duração de três horas. Dessa forma, além de proporcionar o aprendizado a partir da própria experiência de atendimento, ouvir a condução dos colegas em seus respectivos casos durante a supervisão em grupo pluralizava as vivências clínicas.

É importante que se diga desde o início que um relato de experiência clínica em psicanálise não tem a pretensão de descrever uma série de sessões, de ser rigidamente cronológico, ou resumidamente didático. Um relato clínico é, antes de tudo, um dizer sobre a prática de uma função, a função analítica. Cada sujeito que ocupa tal função ouvirá um analisando a partir de sua própria experiência com o inconsciente, a partir daquilo que ele mesmo pôde construir em sua análise pessoal, supervisão e estudos teóricos (Freud, 1919).

O que isso nos diz? Que a psicanálise não é uma ferramenta de pragmatismo, não é uma ciência que se pretende ser utopicamente exata, não é um conjunto de técnicas a serviço de um ideal empírico. A psicanálise é, essencialmente, uma operação na dimensão da linguagem, em tudo aquilo que a linguagem comporta de equívoco, de obliquidade, de ambivalência semântica. Justamente por habitar a linguagem, a psicanálise não poderia se propor a assumir uma rigidez metodológica para dispersar o malentendido, pois é precisamente aí - na equivocação, no desafio ao sentido - que a verdade, estruturada como ficção, fala - para aqueles que estão dispostos a ouvir. (Lacan, 1955).

\section{Caso Clínico}

O caso narrado a seguir foi estruturado a partir de 20 atendimentos que se estenderam no decorrer de um ano. Ainda que não seja este o principal propósito deste trabalho, é preciso considerar que a experiência que aqui se sustenta eticamente como psicanalítica se deu nas delimitações de um formato universitário. Espera-se, portanto, que tais articulações possam contribuir para sequentes elaborações a respeito da (im)possibilidade de intersecção entre a dimensão analítica e o campo discursivo das universidades.

O tratamento foi seccionado em três tempos distintos que denotam a posição da paciente no discurso que a engendra. Trata-se de um sofisma que capta as modulações subjetivas que se sucedem como efeitos da experiência analítica. "Isolam-se no sofisma três momentos da evidência, cujos valores lógicos irão revelar-se diferentes e de ordem crescente. [São eles:] o instante de olhar, o tempo para compreender e o momento de concluir" (Lacan, 1966, p. 204). 
Para as finalidades deste relato, podemos conceber o "instante de olhar" como um tempo em que a paciente ainda está numa posição de completa alienação aos significantes que articulam sua demanda. O "tempo para compreender" se apresenta aqui com a reelaboração discursiva que permite à paciente retificar-se no seu sofrimento. E o "momento de concluir" se dá num ato de invenção que abre a possibilidade para que ela crie uma nova relação com sua forma de gozar.

\section{Instante de Olhar: Só Focada/Sufocada}

A paciente em questão é do gênero feminino, tem 35 anos, é casada, e tem quatro filhos (17, 16, 12 e 05 anos). Os três mais novos são filhos do atual companheiro. O mais velho, é de um relacionamento anterior. Aqui, atribuiremos a ela o nome de Teresa.

Acomodando-se na cadeira da sala, a primeira coisa que Teresa diz sobre as razões de sua presença ali na clínica é que o motivo que a levou até lá, é o mesmo de antes. "O mesmo de antes", é uma frase que traduz muito bem a novela sintomática do neurótico, que é um sujeito que se encontra aprisionado no ímpeto de repetir as cenas de um roteiro estabelecido pela própria fantasia. A fantasia é um roteiro pessoal do qual somos autores, é uma "obra de ficção" (Freud, 1909, p. 221) que nos permite ordenar nossa relação com a falta. $\mathrm{O}$ agravante disso é que o neurótico segue um roteiro sem saber que ele mesmo foi quem o escreveu.

Isso que se repete sintomaticamente na vida de Teresa é a conflituosa relação com o filho mais velho, que para os propósitos deste relato, chamaremos de Marcos. Segundo a queixa da mãe, Marcos saiu da escola, largou o emprego, está fumando maconha e tem um possível envolvimento com o tráfico de drogas na região onde mora.

Neste momento, Teresa só fala do filho mais velho. $\mathrm{O}$ marido, os outros filhos e ela mesma, só aparecem como coadjuvantes de histórias nas quais Marcos é sempre o personagem principal. Quando perguntada sobre outros aspectos da sua vida para além de Marcos, Teresa responde: "Eu estou só focada nisso". A interpretação em Psicanálise surge pelo lapso, ela inaugura o equívoco no qual antes prevalecia uma certeza. Nesse sentido, Lacan (1969-1970) diz que “a interpretação analítica está, ela própria, na contramão do sentido comum do termo” (p. 15). Apoiado nisso, não me ative ao significado da frase, mas sim aos significantes que representavam Teresa como sujeito na relação com o filho, estabelecendo, assim, a conveniência da marcação, devolvo a mensagem emitida por Teresa: "Só focada nisso". O efeito desse manejo de linguagem possibilitou a Teresa articular um novo significante em seu discurso. Levando então as mãos até o pescoço, ela rearranja a frase e diz: "Eu estou sufocada nisso". Só focada e sufocada são variáveis de significantes que denotam o momento que Teresa vive na relação com Marcos, um momento de "só foco" e de "sufoco".

$$
\text { Ainda nas primeiras sessões, Teresa }
$$
conta que comprou uma moto para Marcos e que estava preocupada pelo fato de que ele ainda era menor de idade, e que se algo acontecesse, ela é que iria ser responsabilizada. Ela falava: "Eu respondo por tudo que ele faz". Conta então que gostaria de emancipá-lo para poder passar a moto para o nome dele. Ressalto esse termo e digo que é um conceito interessante, já que emancipar alguém é proporcionar a essa pessoa a 
possibilidade de responder por si mesma. Nesse instante Teresa afirma: "É, ele tem que começar a ser responsável pelo que faz".

Em outra sessão, enquanto Teresa relatava o excesso de preocupação que tinha com o filho mais velho, ela diz: "Eu vivo por conta dele". Minha intervenção se limita em uma devolução interrogativa da frase de Teresa, com um carregado tom de estranhamento, "Vive por conta dele?”. Essa intervenção movimenta algo em Teresa, que engajada numa relação transferencial supõe que eu deseje que ela diga de algo mais, no caso, dos outros filhos.

A transferência é a suposição do analisando de que o analista detém a verdade sobre o enigma do seu sintoma (Lacan, 19601961), e a busca por essa verdade faz com que o analisando se pergunte em relação ao analista: "O que ele quer que eu diga?”. É por esse movimento transferencial que Teresa diz que se preocupa tanto com Marcos que acaba esquecendo-se dos outros filhos, e conclui, "Eles também precisam de mim né?". Nesse ponto, sustentando essa demanda transferencial, respondo: "Sim".

Uma cena que bem representa esse primeiro momento se dá quando Teresa recebe um telefonema e é informada de que Marcos sofreu um acidente de moto. Logo após o ocorrido, quando Teresa chega ao local onde o filho tinha acabado de se acidentar, o encontra rodeado de pessoas. Quando ela chega até Marcos, o abraça efusivamente, o que se segue parece ilustrar a dinâmica da relação entre os dois. Marcos se desvencilha dos braços da mãe e diz: "Ah mãe, eu estou aqui todo dolorido e você vem me abraçar", e com visível pesar nas expressões, Teresa completa, "Aí eu soltei". A intervenção vem na sequência: "É difícil pra você soltar esse filho né??". E em meio a um choro compulsivo, Teresa responde: "É, é muito difícil".

Para encerrar essa primeira parte, é aqui que nós podemos destacar a demanda com a qual Teresa chega à clínica, ela solicita que eu a ajude a emancipar subjetivamente o filho mais velho, ela demanda ajuda para se haver com essa relação de "só foco" com Marcos, e se dá conta de que estar só focada nisso, é, fundamentalmente, estar sufocada nisso. Teresa precisa respirar os ares de um reposicionamento subjetivo na relação com o filho.

\section{Tempo para Compreender: Retificação Subjetiva e Des-Foco}

Este segundo momento é desencadeado pelo fato de que Teresa um dia viu Marcos traficando drogas ao lado da casa, e na conversa que ela teve com o filho por esse motivo, os dois discutiram, e Marcos, afirmando que a mãe não largava do seu pé, resolve pedir seu documento de identidade, que ficava com a mãe, e sair de casa.

$\mathrm{Na}$ noite em que o filho saiu, Teresa diz que não conseguiu dormir, que teve uma crise nervosa e pensou que fosse ficar louca. Só se acalmou com o acolhimento do marido, que a abraçou e disse que ela estava vivendo duas vidas, e que deveria seguir em frente com a vida dela, já que o filho não queria ser ajudado.

É indispensável ressaltar que o marido só entra em cena na perspectiva de Teresa quando Marcos se ausenta. O resultado do ocorrido é que Marcos foi morar num cômodo que pertence à mãe e que fica a algumas quadras de sua casa. Nesse momento, Teresa diz que a proximidade 
com o filho tem sido difícil de ser sustentada, que não aguenta vê-lo fazendo "coisas erradas" sem fazer nada. Ela diz que tem pensado em mudar dali, mudar para outro bairro seria, segundo ela, a única solução para não ter que ver o filho se envolvendo com "coisas erradas".

Faço um apontamento que se direciona para o "só foco" de Teresa, inserindo com a queixa do sofrimento de ver o filho fazendo "coisas erradas" a inércia de seu olhar para o filho. Ela diz: "É, eu estou focada nisso". Utilizo a voz para servir-me novamente do equívoco: "Você está sufocada nisso".

Foi nessa etapa do tratamento que Teresa pôde revisitar sua história a partir de outra posição. Lembra que quando engravidou de Marcos estava com 17 anos e foi logo em seguida abandonada pelo namorado, pai da criança, que queria que ela fizesse um aborto. A negação de Teresa a essa proposta levou ao término do relacionamento. Logo em sequência, ela associa a isso - a fala de uma amiga, que sugeriu - que, já que Teresa não queria abortar, que ela tivesse o filho, mas que depois se desfizesse dele, dando-o para adoção. Após o fim de seu relacionamento com o pai de Marcos, Teresa vai morar com a mãe, que não aprovava nem um pouco a ideia de que sua filha seria mãe solteira.

Em pouco tempo que havia voltado a morar com a mãe, Teresa conta que ao andar pelas ruas do bairro algumas pessoas, aproximando-se dela, diziam: "Se for menino eu quero tá!", enquanto outras: "Ah, se for menina eu vou querer". Teresa então descobre que sua mãe falava para os conhecidos que ela não ficaria com a criança, que Teresa doaria o bebê quando ele nascesse.
Quando foi perguntado, na sessão, como é que ela se sentia diante de todas essas convocações para se livrar do filho, ainda não nascido, Teresa conta que às vezes ficava sozinha no quarto, conversando com o filho, ainda em seu ventre, e dizendo que ela o amava muito, e que nunca iria abandoná-lo.

A fantasia de Teresa parece se estruturar sob a premissa de que amar o filho, nunca abandoná-lo, é viver por conta dele, estar só focada nele. Essa relação com Marcos sustenta para Teresa um lugar no qual ela pode se reconhecer. Lugar de ser toda-mãe para o filho, função em que ela está radicalmente identificada, por isso a separação do filho é vivenciada com tamanha dose de angústia, soltar o filho é, para Teresa, equivalente a abrir mão do gozo de ser a que "reponde por tudo o que ele faz".

Neste período, Teresa se distancia como pode de Marcos, relata tratá-lo até com indiferença nos eventuais encontros que ocorriam entre os dois, chega a passar sessões inteiras sem falar absolutamente nada sobre o filho mais velho, e começa a ampliar o foco para as outras relações de sua vida, por exemplo, sua relação com o marido.

Quando Teresa passa a olhar também para outros aspectos de suas relações, ela acaba vendo coisas que antes, devido ao só foco em Marcos, ela não podia enxergar. Uma delas foi a descoberta de que seu marido vinha tendo um caso com a vizinha, um acontecimento que a fez dirigir o olhar ao seu casamento. Depois de conversar com o marido e cogitar um possível divórcio, os dois resolvem continuar juntos.

Teresa diz numa sessão que também se vê com uma parte de responsabilidade pelo que aconteceu, relata que estava ausente, distante com 
o marido, e que os dois se propuseram a serem mais presentes um para o outro, mais próximos na relação. Só pelo des-foco, na relação com o filho, Teresa pôde reposicionar-se na relação com o marido.

\section{Momento de Concluir: Esvaziamento de} Gozo e Invenção

Como conceito psicanalítico, gozo não é sinônimo de orgasmo, prazer sexual. Falamos de gozo em psicanálise para dizer de algo que produz desprazer no nível da consciência, mas que ao mesmo tempo resulta em satisfação na instância do Inconsciente. O Gozo é a marca daquilo que impele à repetição sintomática e faz com que os sujeitos, ainda que em sofrimento, se apeguem narcisicamente aos seus sintomas.

No caso de Teresa, é evidente que o "só foco" de seu olhar em Marcos resulte em sofrimento, em "sufoco". No entanto, estar só focada nisso também gera satisfação inconsciente, na medida em que ela, a partir do excesso de olhar, sustenta uma identificação narcísica com o filho, de ser aquela que "vive por conta dele". A mãe que se recusou a abrir mão do filho, mesmo diante de tantas convocações para isso, subjaz, todavia, devastada nesse enlace. Como Freud (1919) nos adverte, “o amor dos pais, tão comovedor e no fundo tão infantil, nada mais é senão o narcisismo dos pais renascido, o qual, transformado em amor objetal, inequivocamente revela sua natureza anterior" ( $p$. 98). Exatamente ali onde ela mais sofre, é também onde mais goza.

Neste $3^{\circ}$ momento, presenciamos um remanejamento de Teresa na relação com seu gozo. Depois de se reposicionar no casamento, ela também reconfigura a relação com Marcos, que volta a morar com ela, e na ausência do "só foco" da mãe e por razões que certamente nos escapam - não é Marcos que está em tratamento -, abdica dos negócios com o tráfico de drogas e passa a trabalhar em um comércio da família ao lado de Teresa.

Durante todo o processo do tratamento, Teresa enunciava sua particular relação com o estatuto do olhar e, em uma das últimas sessões, narra uma cena que articula a inauguração de um saber fazer com esse gozo escópico. Conta que em um determinado dia sua cunhada veio avisá-la de que a polícia estava na esquina tirando fotos de um grupo de jovens no qual Marcos estava presente, e que se reunia com frequência naquele lugar para fumar maconha. Teresa diz que na hora se sentiu muito angustiada e teve enorme vontade de ir lá olhar o que estava acontecendo. Relata que antes teria ido "na hora", mas que agora sabia que se fosse lá, ficar olhando, iria se sentir muito pior do que já estava, e que então resolveu não olhar queda do objeto escópico. E conclui dizendo que está aprendendo a "convi(ver) com isso".

O significante elegido por Teresa para dizer dessa sua nova posição diante do ímpeto de olhar aquilo que lhe traz sofrimento, "convi(ver)", representa uma nova posição, ao mesmo tempo que demarca a permanência da dimensão do olhar. O sucesso de um processo analítico não é mensurado pela eliminação de um sintoma, mas sim por um reposicionamento do sujeito em análise em relação a sua forma particular de gozo. No caso de Teresa, seu jeito particular de se haver com o estatuto do olhar, um olhar que ainda aparece, como antes, mas não da mesma forma. 


\section{Discussão}

Podemos postular no fim da construção deste caso que a fantasia de Teresa se confecciona na prerrogativa de ser toda-mãe para Um-filho. $\mathrm{O}$ olhar da analisante fica assim monopolizado nesse Um-filho, que para ela encarna o falo, ou seja, o objeto do qual se supõe trazer a completude, que ausenta a falta (Dor, 1992).

Nós sabemos com Lacan (1962-1963) que quando um sujeito se vê diante da falta da falta, o que se imprime como experiência vivente e sinaliza a invasão do real, tem o nome de angústia. $\mathrm{O}$ que relata a paciente em sua posição enunciativa é que o "só foco" no Um-filho-falo a deixa "sufocada" na angústia do gozo. A direção do tratamento, então, se orientou para estabelecer um corte, operar uma cisão onde a paciente se aliciava com o falo, avatarizado, no Um-filho. E para isso, ela precisou as(sentir) a castração, e se haver com o não-todo do feminino para, inclusive, poder desejar como mulher.

A castração, na medida em que é suporte do desejo, promove um esvaziamento do gozo e abre a possibilidade para Teresa dar vazão a sua dimensão desejante. Miller (2014), no trabalho “A criança entre a mãe e a mulher", nos adverte que é preciso que um filho não "suture, para a mãe, a falta em que se apoia o seu desejo" (p. 2). Ou seja, é importante para o sujeito na posição feminina que está tendo acesso à função materna não fazer da criança um objeto fálico que viria para saturar, preencher, velar sua condição de sujeito marcado pela falta, imiscuído na castração.

Portanto, "quanto mais uma criança preenche a mãe, mais ela a angustia, [...] a mãe angustiada é, inicialmente, aquela que não deseja, ou deseja pouco, ou mal, enquanto mulher" (Miller, 2014, p. 5). A experiência analítica incide, então, nesse cenário, para presentificar a falta, para substancializar a ausência na qual pode advir a moção do desejo. Não um desejo com anseios de plenitude, mas necessariamente, um desejo não-todo, marcado pelo que a feminilidade traz de mais íntimo do impossível.

O tema do feminino sempre pairou sobre as indagações de Freud. No texto "Feminilidade" (1932), o precursor da psicanálise aponta para o que seriam as três saídas possíveis de um sujeito feminino diante da assunção edípica. Uma das possibilidades se daria pela recusa do falo, resultando numa inibição sexual. Outra saída seria pela via de um protesto viril, a menina, recusando agora a ausência do falo, se localizaria no que Freud chamou de "complexo de masculinidade". Por fim, a terceira saída possível aventada nessa importante conferência foi concebida por Freud como a transição para uma "feminilidade normal", a saber, a maternidade. O desejo de ter o falo é substituído pelo desejo de ter um filho.

Mas, declaradamente, até mesmo Freud encontrava no enigma do feminino os limites de suas perscrutações teórico-clínicas. Lacan, no seminário 20, "Mais, ainda" (1972-1973), nos apresenta as fórmulas da sexuação, a partir das quais podemos sustentar que a função fálica ainda não responde sobre o que é ser uma mulher. A saída que Freud denomina para a "feminilidade normal" está, igualmente às outras, submetida à lógica fálica. Em Freud, a questão do desejo feminino ainda fica suspensa, e só se dá a ver pela forma de enigma.

Apesar das indefinições de Freud no que concerne ao feminino, uma recomendação feita por ele no fim da conferência "Feminilidade" (1932) nos lampeja com uma faísca de esperança. "Se desejarem saber mais a respeito da 
feminilidade, [...] consultem os poetas" (p. 134). Talvez então nós possamos nos beneficiar da potência lírica que os poetas têm à disposição para apreendermos um pouco mais sobre o caso narrado neste trabalho, e o que ele pôde promover de transformação na experiência da análise de Teresa, que por meio dos percalços da fantasia conseguiu deixar de ser toda-mãe para vir a ser não-toda mulher.

Eu tive uma namorada que via errado. O que ela via não era uma garça na beira do rio. O que ela via era um rio na beira de uma garra. Ela despraticava as normas. Dizia que sen avesso era mais visivel do que um poste. Com ela as coisas tinham que mudar de comportamento [...]. Também ela quis trocar por duas andorinhas os urubus que avoavam no Ocaso de seu avô. O Ocaso do seu avô tinha virado uma praga de urubu. Ela queria trocar porque as andorinhas eram amoráveis e os urubus eram carniceiros. Ela não tinha certeza se essa troca podia ser feita. $O$ pai falou que verbalmente podia. Que era só despraticar as normas. Achei certo. (Barros, 2006, XII)

Esse texto, que Manoel de Barros nomeia de "Um olhar", articula em outra expressão de linguagem, a poética, os principais aspectos que este caso pode elucidar sobre a prática da psicanálise. O que um analista propõe a alguém que o procura nessa função é oferecer a possibilidade para que esse sujeito possa despraticar as normas estabelecidas pela própria fantasia, se haver com o não todo de sua

4 A série "Memórias inventadas" foi editada em encadernação especial, as páginas não são numeradas, dimensão desejante, e inventar uma nova forma de olhar para si mesmo e para o outro. Enfim, uma re-forma, de olhar para a vida.

\section{Considerações Finais}

Como afirma Lacan (1953-1954, p. 89), "o que conta, quando se tenta elaborar uma experiência, não é tanto o que se compreende quanto o que não se compreende". Vamos então ao que não se compreende.

Foi estranhamente conflituoso ocupar um lugar Outro para alguém. A função analítica é um lugar Outro, por ser indissociavelmente marcada pela encarnação da alteridade, uma posição inquietante (Freud, 1919) para aquele que momentaneamente deve suspender suas ancoragens narcísicas e oferecer-se para que alguém possa desaguar-se em busca do caminho das pedras.

Mas o caminho das pedras fustiga os pés dos que ousam trilhá-lo, os quatro pés, uma parceria que avança, retro-cede, retro-age e torna a avançar num contínuo movimento de fiar e des(a)fiar. Par seria se houvesse complementaridade, não há. Trata-se mais de uma ímpar-ceria, uma relação assimétrica que põe em movimento o discurso do inconsciente, sempre atravessado por uma pedra no meio do caminho, uma pedra que independentemente da direção do tratamento sempre está lá, irresoluta, a nos indagar: $\mathrm{O}$ que fazer?

Disseram-me que é necessário desenvolver um "saber-fazer-com-isso", e que esse saber não pode ser ensinado, que é como frequentemente se diz um saber "de outra

apresentando apenas números correspondentes aos textos. 
ordem”. Nesse ínterim eu fui me designando num “eu-não-sei-fazer-com-seja-lá-o-que-isso-for”. A experiência clínica foi estafante, ratificação de uma práxis que parece resistir à compreensão, os conceitos se tornam cada vez mais oblíquos, fugidios, e se esfacelam quando se acredita ter finalmente os apreendidos.

"Se vocês acreditam ter compreendido, vocês certamente estão errados”, debocha Lacan (1953-1954, p. 185). Bem, se assim for, eu delego a mim o consolo de saber-me, ao menos, certamente não-errado, o que de forma alguma implica no seu oposto e, paradoxalmente, ainda me priva até mesmo de qualquer estabilidade que poderia advir de se estar certamente na errância.

\section{Referências}

Barros, M. (2006). Memórias inventadas: a segunda infância. São Paulo: Planeta.

Dor, J. (1992). Introdução à leitura de Lacan: o inconsciente estruturado como linguagem (3a ed.). Porto Alegre: Artes Médicas.

Freud, S. (1996). Romances Familiares. In S. Freud, Edição standard brasileira das obras completas de Sigmund Freud, v. IX (pp. 217222). Rio de Janeiro: Imago. (Trabalho original publicado em 1909 [1908]).

Freud, S. (1996). Sobre o narcisismo: uma introdução. In S. Freud, Edição standard brasileira das obras completas de Sigmund Freud, v. XIV (pp. 77-108). Rio de Janeiro: Imago. (Trabalho original publicado em 1914).

Freud, S. (1996). Sobre o ensino da psicanálise nas universidades. In S. Freud, Edição standard brasileira das obras completas de Sigmund Freud, v. XVII (pp. 185-189). Rio de Janeiro: Imago. (Trabalho original publicado em 1919 [1918]).
Freud, S. (1996). O estranho. In S. Freud, Edição standard brasileira das obras completas de Sigmund Freud, v. XVII (pp. 235-269). Rio de Janeiro: Imago. (Trabalho original publicado em 1919).

Freud, S. Feminilidade (1996). In S. Freud, Edição standard brasileira das obras completas de Sigmund Freud, v. XXII (pp. 113-134). Rio de Janeiro: Imago. (Trabalho original publicado em 1933 [1932]).

Lacan, J. (1986). O seminário, livro I: os escritos técnicos de Frend (B. Milan, Trad.). Rio de Janeiro: Zahar. (Trabalho original publicado em 1953-54).

Lacan, J. (1998). A coisa freudiana ou Sentido do retorno a Freud em psicanálise (V. Ribeiro, Trad.). In J. Lacan (Org.). Escritos (pp. 402437). Rio de Janeiro: Zahar. (Trabalho original publicado em 1955).

Lacan, J. (1992). O seminário, livro VIII: a transferência (D. D. Estrada, Trad.). Rio de Janeiro: Zahar. (Trabalho original publicado em 1960-61).

Lacan, J. (2005). O seminário, livro X: a angústia (V. Ribeiro, Trad.). Rio de Janeiro: Zahar. (Trabalho original publicado em 1962-63).

Lacan, J. (1998). O tempo lógico e a asserção de certeza antecipada - Um novo sofisma (V. Ribeiro, Trad.). In J. Lacan (Org.). Escritos. (pp. 197-213). Rio de Janeiro: Zahar. (Trabalho original publicado em 1966).

Lacan, J. (2007). O seminário, livro XVII: o avesso da psicanálise (A. Roitman, Trad.). Rio de Janeiro: Zahar. (Trabalho original publicado em 1969-70).

Lacan, J. (1985). O seminário, livro XX: mais, ainda (M. D. Magno, Trad.). Rio de Janeiro: 
Zahar. (Trabalho original publicado em 1972-73).

Miller, J. (2014). A criança entre a mulher e a mãe. Revista Opção Lacaniana, 15, pp. 1-15.

Recebido em 26/01/2017

Aprovado em 15/05/2017 